\title{
A Política Externa Turca no Pós-2011: das revoltas arabes à ascensão do Estado Islâmico
}

\author{
Turkish Foreign Policy in Post-2011: from the arab \\ uprisings to the rise of the Islamic State
}

DOI: $10.21530 /$ ci.v11n2.2016.555

Reginaldo Nasser ${ }^{1}$

Willian Moraes Roberto ${ }^{2}$

\section{Resumo}

Com a eclosão das revoltas árabes a partir de 2011, a Turquia adotou uma nova postura externa, mais assertiva, tornando-se ator de suma importância no Oriente Médio, sobretudo na Síria. Entretanto, o país veio a enfrentar limites à sua projeção, e suas respostas a esses problemas acabaram colocando a Turquia ainda mais no centro de uma série de crises. Este artigo, portanto, tem como objetivo compreender por que a Turquia realizou tamanha inflexão a partir de 2011 e como sua estratégia internacional evoluiu frente às transformações no Oriente Médio. Argumenta-se que fatores domésticos e choques externos levaram o país a adotar uma estratégia assertiva de liderança regional, via apoio a grupos que poderiam adotar seu modelo político. Posteriormente, devido a novos choques externos e mudanças domésticas, a Turquia teve de reposicionar-se e mudar seus objetivos, adotando postura mais cautelosa, de contenção de danos. Passou, então, a utilizar-se de sua centralidade estratégica no conflito sírio e suas crises correlacionadas para barganhar frente às grandes potências, tentando consolidar-se como um ator indispensável, a fim de obter suficiente liberdade de ação para enfrentar aquilo que o governo turco considera como principais ameaças ao país - a expansão curda na Síria e o Estado Islâmico.

Palavras-chave: Turquia; Revoltas Árabes; Síria; EUA; Curdos.

\section{Abstract}

With the Arab uprisings' outbreak from 2011 on, Turkey adopted a new assertive foreign policy posture, becoming an important actor in the Middle East, especially in Syria. However,

1 Professor do Departamento de Relações Internacionais da PUC-SP.

2 Pós-Graduação em Relações Internacionais San Tiago Dantas (UNESP - UNICAMP - PUC-SP).

Artigo recebido em 29/09/2016 e aprovado em 03/11/2016. 
the country came to face limits to its international projection, and its responses to these problems ended up putting Turkey even more at the center of crisis. This paper, therefore, aims to understand why Turkey made such inflection from 2011 on and to analyze how its international strategy has evolved in the face of Middle Eastern changes. It is argued that domestic factors and external shocks led the country to adopt an assertive strategy of regional leadership through supporting groups that could emulate its own political model. Later, due to new external shocks and domestic changes, Turkey had to reposition itself and to change its objectives, adopting a more cautions position of damage control. It then began to utilize its strategic centrality in the Syrian conflict and its correlated crisis to bargain with major powers, trying to consolidate itself as an indispensable actor, in order to get enough freedom of action to address what the Turkish government considers as the country's major threats - the Kurdish expansion in Syria and the Islamic State.

Keywords: Turkey; Arab Uprisings; Syria; US; Kurds.

\section{Introdução}

A Turquia, país herdeiro do Império Otomano, tornou-se, durante a Guerra Fria, um importante membro do bloco ocidental, compondo a Organização do Tratado do Atlântico Norte (OTAN) desde 1952. Desde então, a política externa turca privilegiou as conexões com suas alianças ocidentais - Estados Unidos da América (EUA) e atual União Europeia (UE) - e buscou privar-se, de modo geral, de envolvimentos no Oriente Médio. Entretanto, em 2002, com a chegada do Partido da Justiça e Desenvolvimento (AKP) ao poder, a Turquia passou por importantes transformações. Internamente, o novo governo buscou articular as ideias de democracia e Islã, bem como findar o papel de tutela dos militares sobre a política doméstica. Externamente, tentou harmonizar dois vetores da política externa turca, até então excludentes: as relações com o Ocidente e com o Oriente Médio.

Iniciava-se, assim, um período de barganha e pragmatismo da Turquia frente às grandes potências - principalmente EUA, UE e Rússia - e um processo efetivo de redefinição de seu papel no Oriente Médio, marcado pela mediação de conflitos sob a orientação da doutrina “Zero Problemas com Vizinhos” (FULLER, 2008; DAVUTOĞLU, 2008; KINZER, 2008). Essa abordagem, contudo, foi alterada, a partir de 2011, frente à eclosão das revoltas árabes. O pragmatismo cedeu lugar à assertividade, sobretudo na Síria, com o governo AKP passando a apoiar diretamente grupos que poderiam adotar o "modelo turco": um governo de partido 
islâmico em uma burocracia estatal secular (FULLER, 2008; GERGES, 2012). Tal postura foi também incentivada pelo principal aliado do país, os EUA, em um novo momento de aproximação estratégica entre os governos em Washington e Ancara. Em um momento inicial de otimismo, em 2011, a Turquia parecia provar que poderia agir no Oriente Médio e, ao mesmo tempo, manter sua tradicional colaboração com seus aliados no Ocidente.

Porém, com o passar do tempo, uma série de problemas abalou tanto a nova estratégia turca quanto a aliança entre EUA e Turquia (PARK, 2015; COCKBURN, 2015). Não só os esforços turcos e de aliados foram incapazes de derrubar o regime de Assad, como a guerra civil síria radicalizou-se, tendo como uma das consequências a ascensão dos curdos no norte do país - que passaram a ser vistos como uma fonte de ameaças para a Turquia devido aos seus problemas internos com sua própria população curda. Frente à ascensão do Estado Islâmico (EI), em 2014, a Turquia não apenas negou-se a participar da coalizão estadunidense como passou a se opor energicamente à parceria emergente entre EUA e as unidades curdas. Além disso, em 2015, o país envolveu-se na derrubada de um caça russo na Síria, piorando drasticamente as relações entre Ancara e Moscou. Se isso não bastasse, em 2016, o país sofreu uma tentativa de golpe militar, piorando ainda mais suas relações com aliados no Ocidente. Uma das consequências foi um rearranjo nos alinhamentos políticos turcos - observando-se uma nova barganha com a Rússia, em menos de um ano desde o seu pior momento.

Percebe-se, assim, que, desde 2011, a Turquia não só se consolidou como ator central para o futuro da guerra na Síria e da estabilidade na região, como também se envolveu em um novo processo de negociações com as grandes potências principalmente EUA e Rússia - que culminou, em agosto de 2016, com a primeira incursão militar direta turca em território sírio. Portanto, dada a crescente importância estratégica desse país na região do Oriente Médio, entendemos que é essencial responder às seguintes perguntas: por que a Turquia passou por uma inflexão em sua política externa a partir de 2011? Quais foram as estratégias por ela implementadas em meio às profundas transformações no Oriente Médio entre 2011 e 2016 ?

Quatro hipóteses, não necessariamente excludentes, serão verificadas. Em primeiro lugar, que a alteração na política externa turca, em 2011, é significativa e deveu-se a, de um lado, dois principais choques externos - revoltas árabes e relativo desengajamento dos Estados Unidos em relação ao Oriente Médio - e, de outro, às mudanças na política doméstica e na esfera exterior implementadas pelo 
AKP desde que chegou ao poder. Em segundo lugar, que o novo objetivo buscado pela Turquia foi construir-se como uma espécie de liderança regional no Oriente Médio por meio do apoio a grupos que poderiam adotar seu modelo político. Em terceiro lugar, que novos choques externos a partir de 2013 - os golpes contra grupos islâmicos democráticos, a ascensão do Estado Islâmico e a autonomia dos curdos na Síria - atestaram os limites de sua nova política externa. Finalmente, em quarto lugar, que desde então a Turquia passou a utilizar sua posição estratégica no conflito sírio como instrumento de barganha frente às grandes potências, objetivando garantir suficiente liberdade de ação para enfrentar, como preferir, o que o governo turco considera como ameaças - a expansão curda, sobretudo, e o Estado Islâmico.

A fim de alcançar tais objetivos, o presente artigo divide-se em duas seções, além da introdução e das considerações finais. A primeira, "Bases estruturais da política externa turca e a inflexão pós-2011”, procura apresentar, em primeiro lugar, dois tipos ideais entre os quais a Turquia se movimentaria externamente, suas “vocações”: o "kemalismo" e o "islamismo" (ROBINS, 2007; 2013), identificando quem são os atores sociais ligados a tais ideias e o que representam na prática externa do país. Em seguida, utiliza-se o modelo de Hermann (1990) para compreender a alteração de rumo do país em 2011, o que é feito através da identificação de agentes de mudança tanto no âmbito doméstico quanto externo. A seção seguinte, "A evolução da nova estratégia turca: dos limites encontrados à volta ao pragmatismo", objetiva analisar como se deu a implementação da nova política externa turca, apontando, também através do modelo de Hermann (1990), os novos choques externos e variáveis domésticas que forçaram o governo AKP a reorientar a postura internacional do país uma vez mais.

\section{Bases estruturais da política externa turca e a inflexão pós-2011}

A atuação externa da Turquia ao longo da história sofreu os efeitos do legado deixado pelo processo de construção estatal do país. Como Huntington (1996) aponta, a Turquia pode ser vista a partir da divisão entre suas elites governantes, que, em geral, teriam historicamente procurado transformar o país em uma sociedade europeia ocidental, ou em uma sociedade com forte vinculação com a civilização islâmica, dado o legado otomano. Tal tensão teve início com a derrota otomana na Primeira Guerra Mundial e a posterior guerra 
de independência liderada por Mustafá Kemal que culminou, em 1923, no reconhecimento da independência da república turca e a ascensão de Mustafá ao novo governo (CLEVELAND; BUTTON, 2009; AHMAD, 1993). Kemal passou a empreender um grande esforço de mudança radical na sociedade, com o objetivo de "modernizá-la" de tal modo a equipará-la às potências europeias. A nova Turquia deveria abandonar seu passado islâmico e otomano, implementar o secularismo e criar uma nação turca, etnicamente homogênea, diferente do império multiétnico e islâmico ${ }^{3}$ (CLEVELAND; BUTTON, 2009; AHMAD, 1993).

Entretanto, esse processo de inovações realizadas "por cima” - pelo Estado e de maneira autoritária - acabou criando excessos e problemas futuros: produziu-se diversas formas de discriminação e clivagens na sociedade que geraram, segundo Fuller (2008), três problemas estruturais. O primeiro deles seria um legado de autoritarismo e "tutela militar" (KURU, 2012), nunca abandonado pelas elites kemalistas, atestado pela persistência dos militares em interferir na vida política por se considerarem herdeiros do legado de Atatürk. Sempre que consideram que o secularismo ou a pretensa homogeneidade étnica do Estado encontram-se ameaçados, interferem através de golpes, como em 1960, 1971, 1980 e 1997 (KURU, 2012). O segundo problema é a exclusão e supressão das identidades étnicas não turcas, como os curdos, que compõe quase $20 \%$ da população da Turquia, mas que não são constitucionalmente considerados como tais - o que implicou no não reconhecimento de qualquer vestígio cultural ou linguístico curdo, gerando, posteriormente, problemas políticos e securitários graves, majoritariamente com o PKK (Partido dos Trabalhadores do Curdistão) ${ }^{4}$. Por fim, o terceiro problema, de acordo com Fuller (2008), seria a construção da percepção do Islã como uma ameaça, o que acabou alienando grandes setores mais religiosos da população turca, que viam no secularismo estatal uma forma de supressão de suas escolhas religiosas.

Essa tensão, construída durante a formação do Estado turco, perpetuou-se por meio de uma clivagem político-identitária constante na história da república turca (ROBINS, 2007). Essa diferença, segundo Robins (2007; 2013), afetou a política externa do país e pode ser entendida segundo o conceito de "tradição":

3 A monarquia otomana e o califado, pilares que sustentavam a legitimidade imperial, foram abolidos. Aboliu-se a sharia como base das leis e instituiu-se um novo código civil e penal baseado naqueles dos países europeus, retirou-se da constituição o Islã como religião oficial.

4 Desde 1984, o Partido dos Trabalhadores do Curdistão (PKK) iniciou uma revolta armada, com bases no Iraque e na Síria, com o objetivo de formar uma república socialista no Curdistão turco. 
um conjunto de valores e ordenamentos específicos que delimitam o caráter e as preferências de abordagem dos atores. Robins (2007) aplica para a Turquia esse conceito de tradição, que Huntington (1996) chama de "vocação". Dessa forma, a Turquia sofreria influência tanto da tradição/vocação kemalista como da islamista. Grosso modo, traduzem-se como, do lado kemalista, um privilégio às alianças com o mundo ocidental e um quase alinhamento automático com essas (EUA, UE, OTAN), junto de uma preferência pelo não envolvimento no Oriente Médio. Do lado islamista, reconhece-se os benefícios do pragmatismo e de barganhar com outras grandes potências - como a Rússia -, bem como percebese a importância das relações com o mundo árabe-muçulmano e a possibilidade de atuar concomitantemente nessa arena e na europeia-ocidental.

A república turca sempre foi reticente em envolver-se com o Oriente Médio, a despeito de ensaios pontuais de aproximação, havendo predomínio da tradição kemalista em sua política externa - tanto por parte das elites civis tradicionais quanto por pressão dos militares. Será somente com a ascensão do AKP ao governo turco, no final de 2002, que a Turquia efetivamente redefinirá seu papel no Oriente Médio (ROBINS, 2013; KINZER, 2008; DAVUTOĞLU, 2008). A política externa do AKP buscou harmonizar as duas vocações - kemalismo e islamismo - ao buscar aprofundar a relação com a UE ao mesmo tempo em que repactuava seu papel na região, o qual fazia de forma pragmática, buscando boas relações com vários atores (ROBINS, 2013).

Entretanto, a partir da eclosão das revoltas árabes, a abordagem pragmática turca alterou-se. O pragmatismo cedeu lugar à assertividade, sobretudo na Síria, e o país passou a envolver-se em conflitos no Oriente Médio. Mas por que a Turquia passou por essa inflexão em sua política externa a partir de 2011?

Para responder tal questão, é necessário analisar tanto as variáveis externas na região, quanto o contexto doméstico, que se alterou desde a chegada do AKP ao poder. Como ferramenta de análise, utilizaremos o modelo de Hermann (1990), que analisa fatores responsáveis por alterações na conduta externa de um país. Segundo Hermann (1990), estes seriam: 1) a ação do(s) líder(es), 2) a ação dos componentes da burocracia, 3) a estrutura política doméstica e 4) a conjuntura internacional. Nesse sentido, ao identificar uma mudança de curso na política externa de um país, Hermann (1990) separa essas quatro variáveis e procura entender se há continuidade ou mudança. O autor também classifica em diferentes níveis a profundidade dessas mudanças, podendo ser: 1) ajustes - mantêm-se objetivos e meios, mas altera-se a ênfase em determinada política 
(maior ou menor intensidade);2) mudança de programa - mantêm-se objetivos, mas via outros meios; 3) modificação de objetivo - mudam-se os objetivos e, por consequência, os meios; e 4) alterações fundamentais - mudanças profundas e raras que resultam na total reorientação do país.

A aplicação do modelo de Hermann (1990) no caso turco permite comparar o momento anterior e posterior à mudança em 2011, apontando: 1) continuidade em relação à ação do líder, com a permanência da centralidade do primeiro-ministro Recep Tayyip Erdoğan; 2) continuidade, e mesmo intensificação, da ação dos burocratas, dada a chegada do influente Ahmet Davutoğlu ao posto de ministro das Relações Exteriores desde 2009; 3) mudança na estrutura política doméstica, frente à diminuição da capacidade de interferência política dos militares, possibilitando maior liberdade ao governo; 4) grandes mudanças na conjuntura internacional, com um choque externo causado pelas revoltas árabes e pela percepção da opção do governo dos Estados Unidos em seguir com seu desengajamento seletivo da região. Como resultado, a mudança na política externa turca teria se dado no nível de "mudança de programa": o objetivo continua a ser criar influência na região do Oriente Médio e tornar-se um Estado central (DAVUTOĞLU, 2008), mas os meios são alterados, gradualmente abandonando o pragmatismo e a doutrina de "Zero Problemas com Vizinhos” e empregando uma via de ação mais assertiva, com envolvimento em conflitos ao lado de grupos que poderiam adotar o exemplo do modelo político turco na região (Figura 1).

Figura 1 - Agentes de mudança para reflexão na política externa turca em 2011

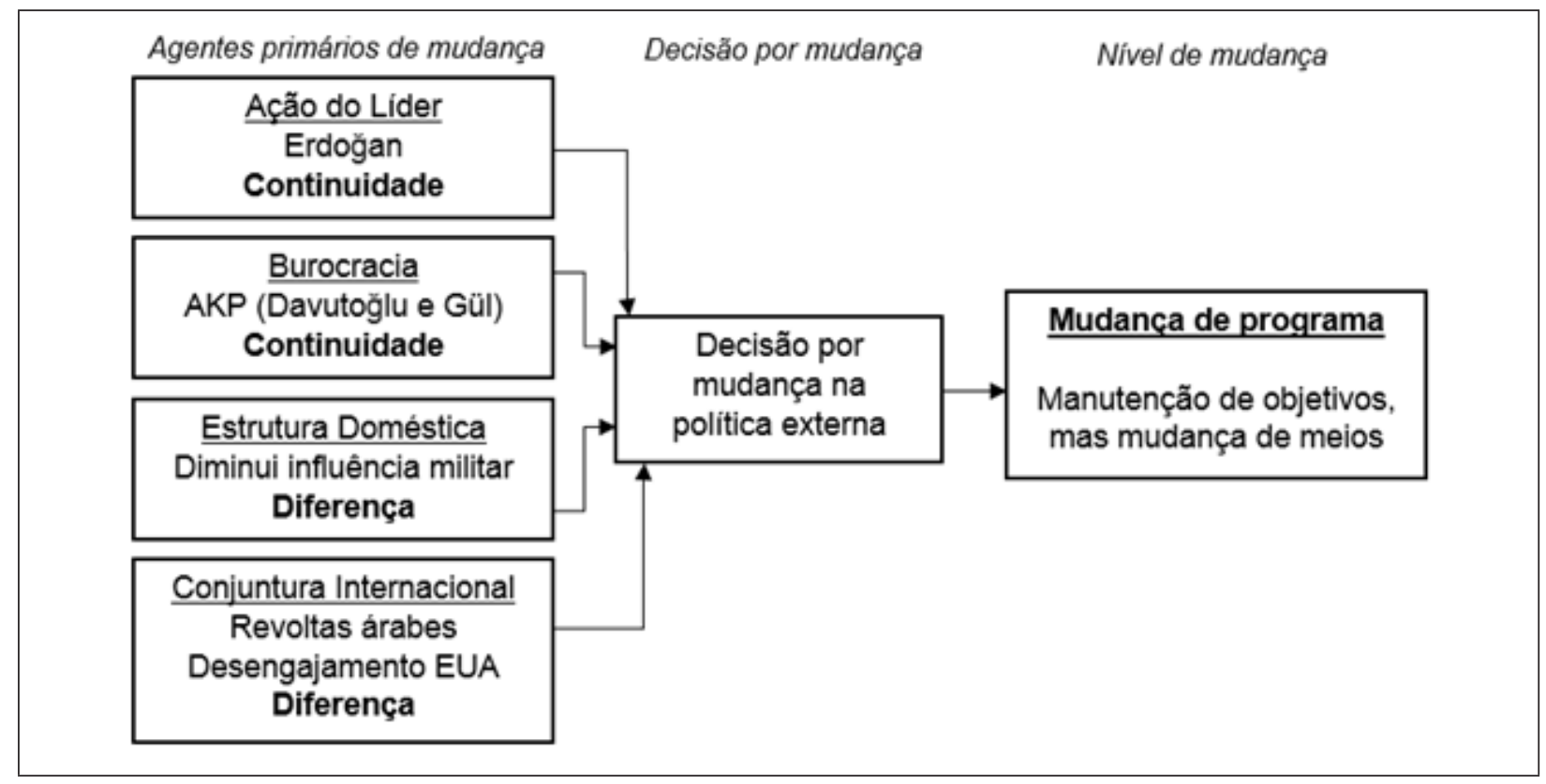

Fonte: elaboração própria. 
A chegada de Erdoğan ao posto de primeiro-ministro e o advento do AKP ao poder marcou o início de um "período de coabitação" no governo turco (ROBINS, 2007), onde um partido com raízes islâmicas foi obrigado a governar junto a um aparato estatal kemalista, que tinha o laicismo como base de sua visão de mundo. A convicção central do partido e de Recep Tayyip Erdoğan era a de que democracia e Islã não eram incompatíveis, e que, inclusive, o maior desejo de grande parte dos turcos era poder desfrutar de ambos (KINZER, 2008). Erdoğan também defendia uma outra interpretação do secularismo, não mais como a supressão das escolhas religiosas individuais, como empregado pela elite kemalista, mas como a liberdade do indivíduo de poder escolher no que acredita (KINZER, 2008). Essa tentativa de harmonização entre democracia e Islã foi fundamental para tentar resolver um dos problemas estruturais apontados por Fuller (2008): o da percepção do Islã como ameaça.

Em sua campanha, em 2002, Erdoğan também pregava uma "normalização" da política, o que significava que os resultados eleitorais deveriam ser respeitados. Buscava-se, assim, resolver o outro problema estrutural, o da tutela militar sobre a política doméstica (KINZER, 2008). Mas, desde o início, o AKP optou por evitar uma confrontação direta com o establishment kemalista, diferentemente do antigo partido islâmico nos anos 1990, o Partido do Bem-Estar de Necmettin Erbakan. Nesse sentido, a criação do AKP, em 2001, foi o resultado de um processo de amadurecimento dos grupos islâmicos e sua visão em relação à democracia (FULLER, 2008).

Em relação à política externa, quando Erdoğan assumiu o posto de primeiroministro, deixou claro que sua primeira prioridade seria liderar a Turquia em direção ao posto de membro da UE, o que surpreendeu a elite kemalista (KINZER, 2008). Essa opção do governo se deu não apenas para consolidar a imagem de que o AKP era um partido "pós-islâmico" e, portanto, pragmático, podendo seguir a tradição kemalista (ROBINS, 2007), mas também para impulsionar reformas domésticas que tirassem poder político dos militares - ou seja, buscou uma forma indireta para enfrentá-los. A busca pela aproximação com a Europa seria, portanto, a característica principal da primeira fase da política externa do governo AKP, entre 2003 e 2005 (ROBINS, 2013). De fato, a aproximação com a UE serviu, domesticamente, para dar início a um processo bem-sucedido de diminuição do poder político dos militares, o que incorreu, utilizando a terceira variável de Hermann (1990), em uma mudança na estrutura política doméstica do país ${ }^{5}$.

5 Em 2003, o parlamento turco aprovou um pacote de reformas que transformou o Conselho de Segurança Nacional (CSN) em um órgão de aconselhamento, removendo sua influência sobre o governo e a burocracia. 
Entretanto, à medida em que diluía a ameaça interna de golpe militar através dos pacotes legislativos, o governo AKP começou a sofrer derrotas políticas em sua relação com a UE, o que foi enfraquecendo o argumento da Turquia para aproximar-se do bloco europeu. Problemas em relação ao Chipre e nas negociações de acesso à UE fizeram com que a atração que a Europa exercia sobre a política externa turca esmorecesse, o que possibilitou uma aproximação maior em relação ao Oriente Médio, região também central para a nova estratégia encabeçada por Ahmet Davutoğlu e Abdullah Gül - ministro das Relações Exteriores até 2007 (ROBINS, 2013).

Ahmet Davutoğlu, acadêmico de relações internacionais e diplomata de carreira, serviu como assessor-chefe de Erdoğan entre 2003 e 2009, como ministro das Relações Exteriores entre 2009 e 2014 e primeiro-ministro entre 2014 e 2016, e foi o responsável por criar as bases conceituais da política externa do AKP no período. Davutoğlu postulava a ideia da Turquia se tornar um "Estado central” com “profundidade estratégica”. Para Davutoğlu (2008), a posição geoestratégica turca permitiria ao país que ele fosse mais do que uma simples ligação entre duas áreas geográficas: a Turquia deveria tornar-se um Estado central, aquele que, por conter múltiplas identidades regionais - europeia e oriental -, deveria manobrar de forma ativa em várias regiões simultaneamente. Deveria ter, portanto, uma ação externa ativa e criativa, com promoção de iniciativas diplomáticas em todas as regiões ao seu redor - uma clara crítica ao excesso de atenção em relação à Europa da vocação kemalista.

Essa política externa pautar-se-ia pela doutrina dos "Zero Problemas com Vizinhos". A Turquia agiria como provedora de ordem, estabilidade e segurança em seu entorno ao engajar-se pragmaticamente com todos os atores possíveis, incentivando o uso da diplomacia para resolução de conflitos e aprofundamento das relações econômicas como forma de criação de interdependências (DAVUTOĞLU, 2008). Como consequência, a diversificação de parcerias geraria maior autonomia para o país, garantindo o que ele chamava de "profundidade estratégica" (DAVUTOĞLU, 2008). Esse é o conteúdo programático de política externa que mudou a Turquia nos anos 2000 e que continuaria baseando, segundo as variáveis do modelo de Hermann (1990), a ação do líder e da burocracia estatal a partir de 2011. O foco predominantemente no Oriente Médio seria marca da segunda fase da política externa turca sob o governo AKP, entre 2005 e 2011, reforçando a ideia de que a política externa turca começava a seguir a vocação denominada islamista (ROBINS, 2013). 
Diversas foram as iniciativas que apontavam para a consolidação da Turquia como ator de grande influência na região. Destacam-se, dentre as várias: a melhora significativa nas relações com a Síria; o reconhecimento do resultado das eleições palestinas de 2006 que deu a vitória ao Hamas e o posterior engajamento político com o grupo, mesmo à contragosto dos aliados ocidentais; o estabelecimento de relações comerciais e a criação de interdependência energética com o Governo Regional do Curdistão iraquiano, através de investimentos em oleodutos; a aproximação com o Irã e o acordo nuclear firmado junto ao Brasil em 2010, também contrário aos interesses dos aliados ocidentais; e, por fim, a escalada de tensões com Israel, que envolveu sérias acusações de Erdoğan à Shimon Peres no Fórum Econômico Mundial em Davos após a guerra israelense contra Gaza em 2009, e culminou com o rompimento das relações diplomáticas entre os dois países em 2010, após incidente onde civis turcos, em uma flotilha no Mediterrâneo, foram mortos em uma operação militar de Israel (ROBINS, 2013).

Além disso, cabe destacar que o modelo político turco de coabitação de um partido islâmico em uma burocracia estatal secular também passou a receber destaque. Diversos acadêmicos, principalmente ocidentais, passaram a vê-lo como uma possível fonte de poder brando e exemplo para os países árabes e muçulmanos. Os Estados Unidos foram mais rápidos que os europeus em perceber os potenciais da Turquia em ser um modelo de governança, pois seria uma forma de aliviar a visão do conflito de civilizações e, possivelmente, colaborar para a estabilização de uma região tão sensível (GERGES, 2012; ROBINS, 2013). Essa é uma mudança bastante significativa, pois sinaliza que o principal país ocidental aliado da Turquia incentivava a tradição islamista de sua política externa, parecendo também crer que é possível harmonizar ambas as vocações turcas.

Entretanto, esse processo de aproximação da Turquia com o Oriente Médio se defrontou com o choque externo a partir do início das revoltas árabes, uma das variáveis de Hermann (1990) - conjuntura internacional - que é fortemente alterada. Naquele momento, uma série de grupos islâmicos passaram a se apresentar como um novo modelo político para seus países, após anos de regimes autocráticos e de repressão à oposição, organizada em partidos como a Irmandade Muçulmana. Havia a percepção de que tais grupos islâmicos poderiam alçar-se ao poder e então implementar um regime relativamente mais aberto que seus antecessores (GERGES, 2012). Diante desse contexto, o governo turco percebeu como uma oportunidade o fato de que vários desses movimentos olhavam para a Turquia como fonte de inspiração. Portanto, a partir de 2011, o governo em Ancara passou a desenvolver uma política externa que procurava capitanear os movimentos regionais que 
eventualmente viessem a emular o modelo turco (GERGES, 2012; ROBINS, 2013).

Esse movimento de inflexão na política externa turca contava com o apoio dos EUA, principal parceiro securitário, que vinha diminuindo sua presença diplomática e militar no Oriente Médio sob a presidência de Barack Obama (GERGES, 2012). Tal desengajamento relativo dos EUA também significava que, em vez de o governo em Washington ter de assumir sozinho responsabilidades securitárias no Oriente Médio, esperava que os próprios atores regionais assumissem maiores compromissos (GERGES, 2012). Dentro dessa lógica, a aliança com a Turquia ganhava destaque. Com a eclosão das revoltas árabes, o governo em Washington não apenas apoiou e incentivou a ideia do modelo turco como exemplo aos movimentos regionais, como aproveitou-se do fato de a Turquia ter assumido um papel proeminente frente à oposição síria (GERGES, 2012).

Portanto, percebe-se que, a partir de 2011, a Turquia passou a adotar uma política externa mais assertiva, tanto em razão da eclosão das revoltas árabes quanto do incentivo trazido pelo relativo desengajamento dos Estados Unidos no Oriente Médio - o que identificamos como mudanças na variável conjuntura internacional de Hermann (1990). O país passou a utilizar-se da ideia de liderança regional por meio de seu modelo político, que poderia ser adotado por grupos que receberiam apoio turco. Essa nova postura se deu em virtude da doutrina de política externa do governo AKP - envolvendo, assim, tanto a variável "ação do líder”, Recep Tayyip Erdoğan, quanto a variável "burocracia”, que continuava seguindo a visão de Davutoğlu e mesmo de Gül. O AKP, ainda, via-se mais livre para implementar sua nova política externa em virtude da diminuição do poder político dos militares graças às reformas ligadas aos pacotes de harmonização legislativa da UE - uma mudança na variável "estrutura política doméstica”.

Assim, depois da inflexão externa turca, mantiveram-se seus objetivos de projetar-se como Estado influente na região, mas mudaram os meios de atuação - uma "mudança de programa”, segundo a classificação de Hermann (1990).

\section{A evolução da estratégia turca: dos limites encontrados à volta ao pragmatismo}

A nova postura externa da Turquia, a partir de 2011, levou o país a se envolver, sobretudo, no conflito sírio, ao lado da oposição ao governo de Bashar al-Assad, além de apoiar a Irmandade Muçulmana no Egito, representativa de vários grupos islâmicos que resolveram adaptar-se às regras do jogo democrático. 
Em relação à Síria, entre março e agosto de 2011, a Turquia ainda preferiu pressionar o governo de Assad a adotar reformas, devido à proximidade que as lideranças turcas desenvolveram com o líder sírio. Entretanto, desde o início, o governo turco sinalizava apoio à oposição: desde julho, permitia que o Exército Sírio Livre (ESL) operasse a partir da província turca de Hatay e, em agosto, consentiu com a formação do Conselho Nacional Sírio (CNS) em Istambul, o grupo político formal da oposição (PHILLIPS, 2012). É a partir de setembro de 2011, quando as pressões à Assad não surtem efeito, que a Turquia rompe oficialmente as relações com o governo sírio e passa a apoiar diretamente os grupos políticos e a oposição armada contra Assad (PHILLIPS, 2012). Inicia-se, assim, uma segunda fase do conflito, em que o governo turco passa a trabalhar com seus aliados ocidentais e outros países da região, como Arábia Saudita e Catar, para estabelecer uma rede de apoio e suporte aos rebeldes sírios. Recursos militares e financeiros eram enviados até o território turco, dentro do qual haveria uma distribuição encoberta para os grupos de oposição dentro da Síria através das fronteiras da Turquia - pelas quais também foi facilitada a entrada de pessoas que fossem lutar no conflito sírio (COCKBURN, 2015).

No que tange ao Egito, o governo turco apoiou as manifestações contra Hosni Mubarak, desde seu início, em janeiro de 2011. Em setembro, meses após a deposição de Mubarak, Erdoğan realizou uma viagem pelas "capitais libertadas” da Tunísia, Egito e Líbia, onde afirmou que a principal lição que a Turquia poderia oferecer aos árabes era a importância do secularismo (GERGES, 2012). Os laços entre Turquia e Egito aprofundaram-se ainda mais depois da eleição de Mohammed Morsi, da Irmandade Muçulmana, para a presidência egípcia em junho de 2012. Em outubro, Morsi foi convidado a participar da convenção anual do AKP em Ancara, onde declarou que os avanços do partido turco eram admirados pelo mundo inteiro (HURRIYET, 2012). Em novembro, Erdoğan voltou ao Cairo, onde defendeu a política externa de Morsi de diversificar parcerias e sugeriu que uma aliança turco-egípcia garantiria paz e estabilidade no Mediterrâneo (CAGAPTAY; SIEVERS, 2015).

Entretanto, com o desenrolar dos conflitos no Oriente Médio, a política turca passou a encontrar problemas que atestariam seus limites. Sofrendo diversos reveses, a Turquia parecia perder o protagonismo e a capacidade de articular e definir uma agenda regional. A própria aliança com os EUA, país que incentivara a nova postura turca, foi abalada. Gradualmente, a Turquia passou a enfrentar problemas não só com seus aliados ocidentais, como também com a Rússia. Quais 
foram, portanto, os problemas que motivaram a Turquia a reformular, mais uma vez, sua atuação externa? Qual foi a estratégia por ela implementada em meio às novas transformações no Oriente Médio pós-revoltas árabes?

Utilizando-se, novamente, do modelo de Hermann (1990) para a transformação posterior à 2011 na política externa turca, argumenta-se que há: 1) continuidade mas fortalecimento do papel da ação do líder, Recep Tayyip Erdoğan, que reforça seu poder, tanto no posto de primeiro-ministro como posteriormente no cargo de presidente; 2) continuidade de quadros do AKP na burocracia, tanto no Ministério das Relações Exteriores, entre 2009 e 2014, quanto na posição de Ahmet Davutoğlu no posto de primeiro-ministro entre agosto de 2014 e maio de 2016; 3) mudanças na estrutura doméstica, com um aumento da oposição contra o governo AKP, o que também leva a um aumento na repressão governamental e à tendência de centralização de poder ao redor de Erdoğan; 4) mudanças na conjuntura internacional, com três grandes choques externos - golpes contra grupos islâmicos democráticos, a ascensão do Estado Islâmico e a autonomia dos curdos na Síria (Figura 2).

Figura 2 - Agentes de mudança para inflexão na política externa após 2011

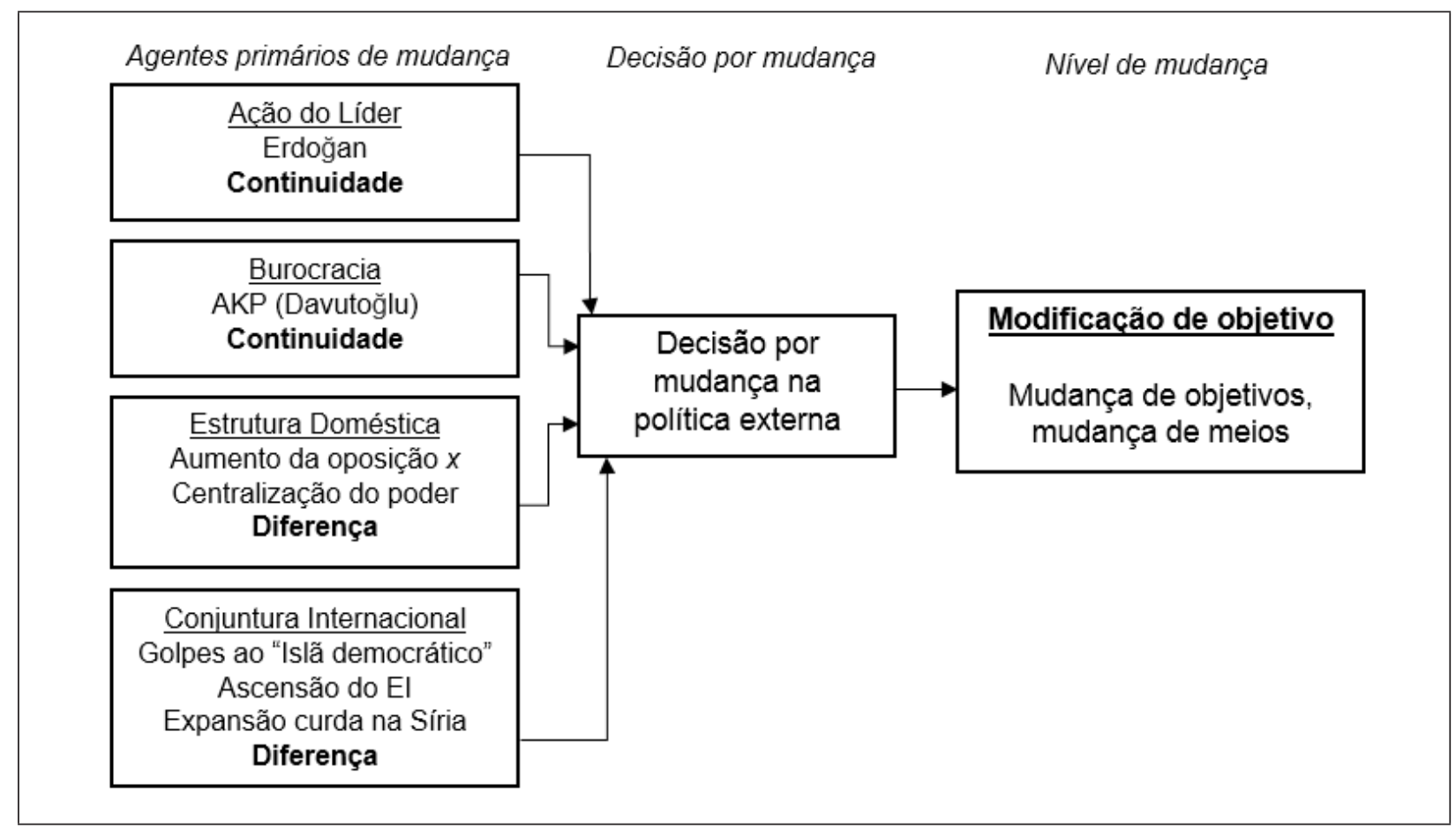

Fonte: elaboração própria.

O reforço do poder do AKP, em meio a um cenário doméstico extremamente polarizado e choques externos que atestaram a incapacidade turca de alcançar 
os objetivos que vinha buscando no Oriente Médio, acabaram produzindo uma mudança no nível de "modificação de objetivo". Não só os meios passariam a mudar, mas também os fins da política externa turca. O otimismo de tornar-se uma liderança regional dá espaço a uma estratégia de contenção de danos, cujo objetivo torna-se enfrentar as ameaças compreendidas como tais pelo governo AKP a partir de então - a expansão curda e o Estado Islâmico. Os meios para tais fins, grosso modo, envolvem barganhas pragmáticas frente às grandes potências, utilizando-se da posição estratégica turca para enfrentar o EI e influenciar a guerra na Síria e o fluxo de refugiados do conflito (Figura 2).

Um dos choques externos que afetou a projeção externa turca e sua ideia de liderança regional através do "modelo turco" foram os golpes e reveses sofridos pelos grupos do "Islã democrático", aqui entendidos como aqueles que eram partidos islâmicos e que aceitavam a participação política através de regras democráticas - como o AKP na Turquia ( $\mathrm{LYNCH}, 2016)$. O primeiro e mais emblemático desses foi a deposição, no dia 3 de julho de 2013, do governo de Morsi e da Irmandade Muçulmana no Egito através de um golpe militar que colocou Abdel Fatah al-Sisi no poder.

O novo governo egípcio adotou uma intensa campanha contra a Irmandade, que logo transformou-se em algo regional, com Egito, Emirados Árabes Unidos e Arábia Saudita declarando-a como uma rede terrorista (LYNCH, 2016). A Irmandade Muçulmana, portanto, passou a sofrer imensa pressão para operar na região, tanto financeiramente quanto em termos organizacionais; sua rede de infraestrutura de serviços sociais foi danificada e diversos dos seus líderes foram presos ou assassinados. Como coloca Lynch (2016) e Barkey (2016), o golpe egípcio acabou reforçando grupos islâmicos radicais ao remover da cena política a mais mainstream das correntes islâmicas. A estratégia da Irmandade, de participação democrática, seguida por vários outros partidos na região, foi desacreditada e parecia reforçar-se a ideia da incapacidade desses grupos - os mesmos apoiados pela Turquia - atingirem seus objetivos através de meios legais e institucionais. Desde então, a Turquia e o Egito romperam relações diplomáticas e Erdoğan manteve sua oposição ao governo do presidente Sisi.

O segundo choque externo de grande importância para a Turquia ocorreu a partir do momento em que os curdos da Síria adquiriram autonomia efetiva sobre o território no norte do país. Os curdos, representados pelo Partido da União Democrática (PYD) e seu braço militar, as Unidades de Proteção Popular (YPG), passaram a ser uma fonte de preocupação para o governo turco, maior 
que o próprio regime de Assad, visto que a Turquia temia ligações entre o PYD e o Partido dos Trabalhadores do Curdistão (PKK) - considerado terrorista pelo governo em Ancara (STRATFOR, 2015) ${ }^{6}$.

De fato, ainda em julho de 2013, Davutoğlu, então ministro das Relações Exteriores, declarara que o governo turco esperava três coisas em relação ao PYD sírio: que não cooperassem com o regime de Assad, que não formassem uma entidade política com bases étnicas ou religiosas, e que não se engajassem em atividades que colocassem em risco a segurança da fronteira turca (GUNTER, 2015). A despeito da declaração, os curdos na Síria, em novembro de 2013, declararam oficialmente sua autonomia na chamada região de Rojava, proclamando, inclusive, uma carta de moldes constitucionais, enfatizando o secularismo e a igualdade de gênero, a qual foi aprovada pela população local em janeiro de 2014. O governo em Ancara não apenas negou-se a reconhecer o movimento, como condenou-o, vendo-o como um insulto às demandas securitárias turcas. Além disso, em março e abril de 2014, o comandante das YPG, já enfrentando grupos radicais islâmicos na Síria, como a al-Nusra, começou a conclamar os curdos dentro da Turquia para que colaborassem com o esforço de combate da comunidade curda de ambos os lados da fronteira - na Síria e Turquia -, o que preocupou ainda mais o governo AKP (GUNTER, 2015).

A preocupação com a expansão curda na Síria aprofundou-se com a ascensão do EI na Síria e no Iraque a partir de 2014 - o terceiro choque externo aqui considerado -, principalmente pelo papel que os curdos sírios desempenhariam no combate contra esse grupo. De fato, na medida em que o EI expandiu-se sobre os territórios sírio e iraquiano, os EUA criaram uma coalizão para realizar ataques aéreos contra o grupo e conter seu avanço; a Turquia, entretanto, mesmo sendo parte da OTAN, negou-se a participar e a ceder sua base aérea em Incirlik, próxima ao território sírio (COCKBURN, 2015).

Isso se deveu, principalmente, à questão curda na Síria: como os EUA não estavam dispostos a enviar forças terrestres diretamente para combater o EI, que também era enfrentado pelo PYD e as YPG, encontrou nas unidades curdas uma das forças terrestres mais efetivas no combate ao grupo extremista (COCKBURN, 2015). Para o governo turco, entretanto, concretizava-se um de seus grandes temores: os curdos na Síria demonstravam sua força ao combater o EI e, assim,

6 O governo Assad, atacado pela oposição apoiada pela Turquia, decidiu retirar a grande maioria de suas Forças Armadas do território curdo, a partir de julho de 2012, sabendo que a consequente autonomia dessa população traria problemas ao governo AKP. Criava-se, assim, uma forma de pressionar os turcos e sua política na Síria. 
recebiam apoio político e material dos EUA. Temia-se que, como consequência, a derrota do EI no futuro trouxesse ao PYD a legitimação, por parte de Washington, aos seus ganhos territoriais.

De fato, em setembro de 2014, quando o EI cercou a cidade síria de Kobane, na fronteira com a Turquia, e os curdos sírios lutaram contra o cerco com apoio dos EUA, o governo turco pouco fez e ainda criticou a ação estadunidense (PARK, 2015). O próprio Erdoğan não apenas afirmou que "o PKK é equivalente ao EI" (PARK, 2015, p. 586, tradução nossa) ${ }^{7}$, como declarou que a Turquia só apoiaria o combate caso os EUA bancassem a ideia de criação de uma "zona tampão" dentro do território sírio, a partir da fronteira turca, o qual serviria para garantir que nem os curdos nem o EI ali permanecessem (KANAT; USTUN, 2015).

Tais choques externos são, portanto, as principais razões para a Turquia ter perdido a capacidade de articular uma agenda regional e ter se recolhido a uma posição mais defensiva. Entretanto, para além disso, fatores internos também abalaram a concepção do modelo político turco - a variável "estrutura doméstica" de Hermann (1990). A partir de julho de 2013, manifestações populares eclodiram em diversos centros urbanos do país contra o governo, o qual respondeu com força para reprimi-las. Desde então, aumentaram as denúncias relacionadas a prisões arbitrárias e ao cerceamento da liberdade de expressão na Turquia (PARK, 2015). Diversos opositores do governo têm sido presos e vários jornais foram fechados, ao mesmo tempo em que Erdoğan, eleito presidente em 2014, dada a larga base de apoio que ainda detém, vem pleiteando a transformação do sistema político turco de parlamentarismo para presidencialismo. Ao mesmo tempo, o governo AKP também vem se engajando em um embate contra o movimento islâmico civil Hizmet, liderado pelo clérigo exilado nos EUA, Fethullah Güllen. Anteriormente aliados, a partir de 2013 os "güllenistas" teriam passado a denunciar esquemas de corrupção envolvendo membros do AKP e do governo, o que levou Erdoğan a publicamente torná-los um de seus principais inimigos políticos (PARK, 2015).

Dessa forma, a aliança com os países ocidentais, principalmente os EUA, ia enfraquecendo-se. De um lado, após a escalada de repressão interna na Turquia e os golpes aos partidos islâmicos regionais, a atratividade do modelo turco ia esmorecendo. De outro, crescia a divergência entre os aliados em relação à principal ameaça a ser combatida na Síria: para os EUA, o foco recaía sobre o EI,

7 Citação elaborada a partir do original: “Erdogan's comment that 'for us, the PKK is the same as ISIL. It is wrong to consider them as different from each other” (PARK, 2015, p. 586). 
enquanto, para a Turquia, recaía sobre a expansão curda síria (COCKBURN, 2015; PARK, 2015). Como, portanto, o governo turco reagiu a tais reveses?

Diante dos novos constrangimentos e limitações, a Turquia iniciou um processo de recuperação de seu pragmatismo externo, passando a utilizar-se de sua posição geográfica estratégica para barganhar com as grandes potências, a fim de buscar garantir suficiente liberdade de ação para enfrentar o que o governo considerava como ameaça. Assim, a ideia de tornar-se uma liderança regional cedeu lugar a uma estratégia de contenção de danos, uma mudança no nível de "modificação de objetivo", segundo o modelo de Hermann (1990). O governo AKP compreendia que os EUA seriam a primeira peça fundamental nesse sentido, visto que o país há tempos cobrava uma postura mais incisiva da Turquia na luta contra o EI. A questão, portanto, era planejar e negociar os termos do engajamento turco no combate ao grupo extremista.

Um importante gatilho que parece ter incentivado uma reação turca aos seus novos problemas foi a eleição geral de junho de 2015 no país (YAVUZ; ÖSCAN, 2015). Pela primeira vez desde que chegara ao poder, o governo AKP perdeu maioria no parlamento, conseguindo apenas $40,9 \%$ dos votos totais, o que levou a 258 assentos de um total de 550 - menos da metade. Se não bastasse, pela primeira vez o partido ligado ao movimento curdo turco conseguiu passar da barreira de $10 \%$ de votos necessários para entrar no parlamento; o HDP (Partido Democrático dos Povos) recebeu 13,1\% dos votos e conquistou 80 assentos no parlamento (YAVUZ; ÖSCAN, 2015). Para Erdoğan e o AKP, a eleição representou uma derrota significativa, sobretudo por ocorrer depois da resolução do cerco em Kobane, que levou a uma vitória das forças curdas e a uma aproximação dessas com os EUA. Agora não apenas os curdos na Síria haviam pleiteado um espaço legítimo na luta contra o EI, como também o partido curdo turco chegara ao parlamento.

O governo turco negou-se a formar um governo de coalizão e novas eleições foram convocadas para novembro de 2015. A fim de vencer o novo pleito e consolidar a posição doméstica, o governo AKP optou por uma nova estratégia nacionalista e assertiva, definitivamente colocando-se contra o EI, mas também contra os curdos, cada vez mais destacados pelo governo como ameaça (YAVUZ; ÖSCAN, 2015). Para tanto, e agindo pragmaticamente, em julho de 2015, menos de um mês após a derrota na eleição, a Turquia finalmente cedeu aos EUA e juntou-se à coalizão contra o EI, permitindo o uso da base aérea em Incirlik e também iniciando ataques aéreos na Síria. Paralelamente, decretou o fim do cessar-fogo que tinha sido estabelecido com o PKK, desde 2013, retomando a 
guerra civil contra o grupo. Dessa forma, o governo turco decidiu, como estratégia, enfrentar simultaneamente as duas principais ameaças por ele percebidas - EI e PKK. Portanto, ao saber que os EUA precisavam do apoio turco na luta contra o EI, Ancara adentrou o embate, ao mesmo tempo em que afirmava que a luta contra o PKK era parte do esforço antiterrorista geral e, assim, devia ser apoiado por seus aliados (STRATFOR, 2015).

Efetivamente, a própria postura do HDP no parlamento facilitou a estratégia do AKP. Desde o fim do cerco em Kobane, em 2014, o PKK já iniciara alguns atentados contra alvos policiais e de lideranças curdas contrárias ao grupo no sudeste da Turquia. Porém, após a vitória do HDP, o partido no parlamento recusou-se a repudiar veementemente as ações violentas cada vez mais recorrentes do PKK (YAVUZ; ÖSCAN, 2015). Paralelamente, atentados perpetrados pelo EI ocorreram em Suruç e Ancara, em julho e outubro de 2015, aumentando o clima de insegurança no país. O governo AKP, diante da situação, alardeava a piora na situação securitária do país, culpando principalmente o HDP, por não conseguir controlar o PKK, pintando-o como "braço político do terrorismo" (YAVUZ; ÖSCAN, 2015). Assim, as eleições de novembro de 2015 ocorreram em meio a uma guerra contra o EI e contra o PKK, e foram marcadas por essa nova ofensiva do AKP. Segundo a análise de Yavuz e Öscan (2015), votos de grupos nacionalistas, que antes votavam no MHP (Partido de Ação Nacionalista), migraram para o AKP, bem como votos de grupos liberais e de esquerda que, tendo antes votado no HDP, passaram a desconfiar de sua ligação com o PKK. Como resultado, o AKP obteve 49,49\% dos votos, 317 assentos no parlamento - obtendo de novo a maioria -, enquanto o HDP caiu para apenas 10,75\% dos votos, agora com 59 assentos.

A entrada da Turquia na luta contra o EI serviu como barganha para efetivamente blindar o governo AKP de diversas críticas por parte da OTAN aos seus problemas domésticos; o apoio dos EUA ao PYD também passou a ser balanceado com afirmações, acalmando o governo turco, de que Washington não apoiaria o separatismo curdo e que condenava os atos do PKK. Para além disso, dois outros fatos serviram de instrumento para a Turquia demarcar sua importância para a aliança ocidental.

$\mathrm{O}$ primeiro deles diz respeito à UE e à crise dos refugiados sírios. O bloco europeu encontra-se em uma grave crise institucional e a questão da entrada de imigrantes é ponto polêmico para os governos da Europa. Nesse contexto, uma das principais rotas de entrada de refugiados no continente europeu é pela Grécia, através do mar Egeu, a partir da Turquia - o que garante a centralidade 
do país nessa questão ${ }^{8}$. Diante do aumento no número de migrantes chegando à UE pela Grécia, em março de 2016 houve a assinatura de um acordo entre o bloco e a Turquia, consolidando ainda mais a posição turca para manobrar frente aos europeus. Em troca do compromisso turco de diminuir o fluxo de migrantes para a Grécia, a UE entregaria 3 bilhões de euros ao governo da Turquia e retiraria a necessidade de visto de seus cidadãos para entrarem no continente europeu.

Entretanto, mais do que um acordo que diz respeito à crise dos refugiados, ou muito menos do que uma volta do privilégio à tradição kemalista de política externa, o compromisso serviu, por parte do governo turco, para colocar a Turquia como indispensável para a resolução do problema. Ao colocar-se como detentora da "porta de entrada" da UE e peça chave na crise humanitária dos refugiados, a Turquia barganhou pelo fato de ser necessária para implementar o acordo e aliviar a pressão migratória para o bloco. Em troca, pleiteou indiretamente uma maior margem de manobra para implementar suas políticas, objetivando comprar o silêncio ou a indiferença europeia contra suas ações, tanto na Síria quanto em âmbito doméstico, frente aos curdos e opositores (STRATFOR, 2016; DANFORTH, 2016).

O segundo fato que atestou a centralidade turca, envolveu a Rússia e ocorreu ao longo de 2015. Quando Ancara barganhou sua entrada no combate ao EI com os EUA, o governo turco pleiteou novamente a implementação de uma "zona tampão" no norte sírio, com suas próprias Forças Armadas e com apoio da OTAN. Oficialmente, seu objetivo seria ali agrupar a oposição à Assad e também reinstalar refugiados; extraoficialmente, serviria também para conter a expansão curda síria, visto que tal zona inserir-se-ia entre duas regiões controladas pelo PYD - Afrin e Kobane (BERNARD; GORDON; SCHMITT, 2015). Entretanto, o governo russo já havia alertado que uma incursão da Turquia na Síria seria problemática para Moscou. Efetivamente, em setembro de 2015, dois meses após a entrada turca na coalizão estadunidense, a Rússia iniciou sua campanha aérea na Síria ao lado do regime de Assad, mandando um sinal aos atores envolvidos.

Em novembro, porém, o governo turco derrubou um caça russo, o que iniciou uma escalada de tensões entre Ancara e Moscou, com o governo russo afirmando que também atacaria forças turcas caso essas intervissem no território sírio (ARKHIPOV; KRAVCHENKO, 2015). Como resultado, a tensão com a Rússia não apenas frustrou momentaneamente os planos turcos, como a possibilidade da Turquia envolver a OTAN em um conflito com a Rússia cresceu. Como a aliança

8 A Turquia também é o país com o maior número absoluto de refugiados sírios, mais de 2,5 milhões. 
militar ocidental procurava evitar um embate de tamanha magnitude com Moscou, as ações do governo turco passaram a ocupar uma posição ainda mais sensível dentro da OTAN, acabando por reforçar ainda mais a centralidade da Turquia na Síria e destacando sua capacidade de alterar a magnitude do enfrentamento com os russos.

Portanto, desde que a Turquia resolveu responder, em julho de 2015, aos constrangimentos que vinha enfrentando, o governo turco recuperou na política externa uma postura pragmática e de barganha entre as grandes potências, sempre se utilizando da centralidade do país no conflito sírio e seus desdobramentos. Com isso, pode colocar-se frente aos EUA como parte indispensável da coalizão contra o EI, ao mesmo tempo em que cobrava da OTAN atenção às suas preocupações em relação ao PYD, apoio na luta contra o PKK e indiferença às repressões domésticas e escalada autoritária. Da UE, o governo turco pode cobrar o mesmo, na medida em que passou a ser uma peça central na crise dos refugiados, colocando-se como porta de entrada do bloco europeu e responsável, em grande medida, pelo controle do fluxo de migrantes em direção à Europa. Em relação à Rússia, sua postura de confrontamento a Moscou, ao longo de 2015, e na primeira metade de 2016, fez com que a OTAN prestasse ainda mais atenção às ações e demandas turcas. Assim, a busca da liderança regional foi substituída pela busca de uma margem de manobra e liberdade de ação, através dessas barganhas, para a nova estratégia de contenção de danos que o governo turco implementou, possibilitando enfrentar o que considerava como ameaça - principalmente a expansão curda e o EI na Síria.

\section{Conclusões}

Desde 2011, a política externa turca para o Oriente Médio alterou-se frente às revoltas árabes, graças também aos incentivos de seus aliados ocidentais, principalmente EUA, que viam no "modelo político turco" uma espécie de guia para as transformações que acometiam a região. Importantes transformações domésticas, desencadeadas pela chegada do AKP ao poder, também foram fundamentais para dar base ao novo ativismo internacional turco. De fato, a partir de 2011, a Turquia gradualmente consolidou-se como um dos mais importantes atores envolvidos na guerra da Síria e, consequentemente, em todos os seus desdobramentos. Entretanto, devido a problemas domésticos posteriores, que foram respondidos por parte do governo com um crescente autoritarismo, e por novos choques externos - os 
golpes contra grupos islâmicos democráticos, a ascensão do Estado Islâmico e a autonomia dos curdos na Síria -, a Turquia passou por uma reformulação em sua política externa, adotando uma postura majoritariamente de contenção de danos e de busca de uma larga liberdade de ação para enfrentar as novas ameaças como preferisse.

Os meios empreendidos em busca de tal objetivo envolveram a utilização, por parte do governo turco, da posição estratégica do país no conflito sírio como instrumento de barganha frente às grandes potências. Os exemplos aqui citados, da Turquia tornando-se parte da coalizão dos EUA, colocando-se como parte fundamental da crise dos refugiados, e enfrentando a Rússia, não são as únicas evidências da nova postura do governo AKP. Recentemente, novos eventos reforçaram ainda mais a estratégia turca de barganha na esfera externa. Após sofrer uma tentativa de golpe militar, em julho de 2016, e superá-la, o governo AKP aproveitou para manobrar e expurgar de cargos públicos seus opositores políticos ligados ao movimento Hizmet. Uma escalada autoritária posterior levou a um estremecimento ainda maior com seus aliados ocidentais, que estavam reticentes em apoiar as ações do governo. Tal distanciamento com o Ocidente levou a Turquia a reatar relações com a Rússia, em agosto de 2016, menos de um ano após as tensões entre Ancara e Moscou. Se isso não bastasse, dias depois ainda houve a visita do ministro de Relações Exteriores do Irã à Turquia, enquanto as YPGs sírias tomavam cidades a oeste do Rio Eufrates - algo considerado pelo governo turco como uma linha vermelha a não ser cruzada pelos curdos.

Ainda assim, no dia 24 de agosto, após reaproximar-se da Rússia e do Irã, o governo turco vê os EUA se reaproximarem após o estremecimento nas relações e apoiarem o lançamento da Operação Escudo do Eufrates, a primeira incursão militar direta da Turquia em território sírio. Não apenas o vice-presidente dos EUA, Joe Biden, esteve presente no país, como os EUA deram suporte aéreo à Turquia e ainda declararam que as YPGs deveriam recuar para o leste do Eufrates caso não quisessem perder o apoio estadunidense. Parece, portanto, que a estratégia da Turquia de usar da barganha pragmática entre as grandes potências, sabendo do valor de sua centralidade no conflito sírio, vem rendendo o apoio necessário para os fins perseguidos pelo governo turco. A Turquia segue, assim, manobrando para garantir-se como uma "potência indispensável" (FRIEDMAN, 2016) e disso tirar os maiores benefícios possíveis. Busca, para tanto, consolidar-se como ator chave na guerra da Síria - ainda mais agora, depois que realizou uma intervenção militar no país -; como necessária para a resolução da crise dos refugiados frente 
a UE e como pêndulo na relação EUA-Rússia - uma ponte entre diversas crises interligadas, portanto.

\section{Referências}

AHMAD, Feroz. The Making of Modern Turkey. Londres: Routledge Press, 1993.

ARKHIPOV, Ilya; KRAVCHENKO, Stepan. Putin Threatens Turkish Jets in Syria as Spat Escalates. Bloomberg, 17 de dezembro de 2015. Disponível em: < http://www. bloomberg.com/news/articles/2015-12-17/putin-damps-hope-for-turkish-detentethreatening-jets-in-syria > . Último acesso em: 25/11/2016.

BARKEY, Henri J. Erdogan's Foreign Policy Is in Ruins. Foreign Policy, 4 de fevereiro de 2016. Disponível em: < http://foreignpolicy.com/2016/02/04/erdogans-foreignpolicy-is-in-ruins/ > . Último acesso em: 25/11/2016.

BARNARD, Anne; GORDON, Michael R.; SCHMITT, Eric. Turkey and U.S. Plan to Create Syria 'Safe Zone' Free of ISIS. The New York Times, 27 de julho de 2015. Disponível em: < http://www.nytimes.com/2015/07/28/world/middleeast/turkey-and-us-agreeon-plan-to-clear-isis-from-strip-of-northern-syria.html?_r $=1>$. Último acesso em: 25/11/2016.

CAGAPTAY, Soner; SIEVERS, Marc J. Turkey and Egypt's Great Game in the Middle East. The Washington Institute, 8 de março de 2015. Disponível em: < http://www. washingtoninstitute.org/policy-analysis/view/turkey-and-egypts-great-game-in-themiddle-east > . Último acesso em: 25/11/2016.

CLEVELAND, William L.; BUNTON, Martin. A History of the Modern Middle East. 4. Ed. Boulder: Westview Press, 2009.

COCKBURN, Patrick. A Origem do Estado Islâmico: o fracasso da "Guerra ao Terror" e a ascensão jihadista. São Paulo: Autonomia Literária, 2015.

DANFORTH, Nick. Erdogan's Epic Europe Trolling. Foreign Policy, 23 de março de 2016. Disponível em: < http://foreignpolicy.com/2016/03/23/erdogans-epic-europe-trollingeu-migrant-refugee-deal/ > . Último acesso em: 25/11/2016.

DAVUTOĞLU, Ahmet. Turkey's Foreign Policy Vision: An Assessment of 2007. Insight Turkey, vol. 10, n. 1, 2008. Disponível em: < http://arsiv.setav.org/ups/dosya/9595. pdf > . Último acesso em: 25/11/2016.

FRIEDMAN, George. The Turkish Week: Caution and Ambition. Geopolitical Futures, 19 de fevereiro de 2016. Disponível em: < https://geopoliticalfutures.com/the-turkishweek-caution-and-ambition/ > . Último acesso em: 26/11/2016.

FULLER, Graham. The New Turkish Republic: Turkey as a Pivotal State in the Muslim World. Washington: US Institute of Peace, 2008. 
GERGES, Fawaz. Obama and the Middle East: the end of America's moment? Nova York: Palgrave Macmillan, 2012.

GUNTER, Michael M. Iraq, Syria, ISIS and the Kurds: Geostrategic Concerns for the U.S. and Turkey. Middle East Policy, v. XXII, n. 1, primavera de 2015.

HERMANN, Charles Frazer. Changing Course: When Governments Choose to Redirect Foreign Policy. International Studies Quartery, vol. 34, n. 1, março de 1990.

HUNTINGTON, Samuel. O Choque de Civilizações. Rio de Janeiro: Ponto de Leitura, 1996.

HURRIYET. Leaders of the region meet at AKP congress. Hurriyet Daily News, 1 de outubro de 2012. Disponível em: < http://www.hurriyetdailynews.com/leaders-ofthe-region-meet-at-akp-congress.aspx?pageID $=238 \&$ nid $=31356>$. Último acesso em: 26/11/2016.

KANAT, Kilic; USTUN, Kadir. U.S.-Turkey Realignment on Syria. Middle East Policy, v. XXII, n. 4, inverno de 2015.

KINZER, Stephen. Crescent and Star: Turkey Between Two Worlds. Nova York: Farrar, Straus e Giroux, 2008.

KURU, Ahmet T. The Rise and Fall of Military Tutelage in Turkey: Fears of Islamism, Kurdism, and Communism. Insight Turkey, v. 14, n. 2, 2012.

LYNCH, Marc. The New Arab Wars: Uprisings and Anarchy in the Middle East. Nova York: Public Affairs, 2016.

PARK, Bill. Turkey's isolated stance: an ally no more, or just the usual turbulence? International Affairs, v. 91, n. 3, 2015.

PHILLIPS, Christopher. Into the Quagmire: Turkey's Frustrated Syria Policy. Chatham House Briefing Paper, dezembro de 2012.

ROBINS, Philip. Turkish foreign policy since 2002: between a "post-Islamist” government and a Kemalist state. International Affairs, v. 83, n. 1, 2007.

ROBINS, Philip. Turkey’s “double gravity” predicament: the foreign policy of a newly activist power. International Affairs, v. 89, n. 2, 2013.

STRATFOR. An Invigorated Turkey Lashes Out. Geopolitical Diary, 28 de julho de 2015. Disponível em: < https://www.stratfor.com/geopolitical-diary/invigorated-turkeylashes-out > . Último acesso em: 26/11/2016.

STRATFOR. The EU and Turkey Reach a Tenuous Immigration Agreement. Stratfor Analysis, 18 de março de 2016. Disponível em: < https://www.stratfor.com/analysis/eu-andturkey-reach-tenuous-immigration-agreement > . Último acesso em: 26/11/2016.

YAVUZ, M. Hakan; ÖZCAN, Nihat Ali. Turkish Democracy and the Kurdish Question. Middle East Policy, v. XXII, n. 4, inverno de 2015. 